\title{
Effects of Egg Shell Membrane Hydrolysates on Anti-Inflammatory, Anti-Wrinkle, Anti-Microbial Activity and Moisture-Protection
}

\author{
Jinhee Yoo ${ }^{1}$, Kimoon Park' ${ }^{1}$ Youngji Yoo', Jongkeun Kim², Heejin Yang ${ }^{2}$, and Youngjae Shin ${ }^{3 *}$ \\ ${ }^{1}$ Department of Food Science and Biotechnology, Sungkyunkwan University, Suwon 440-746, Korea \\ ${ }^{2}$ Sungkyun Biotech Co., LTD R\&D Center, Ansan 425-839, Korea \\ ${ }^{3}$ Department of Environmental Horticulture, Dankook University, Cheonan 330-714, Korea
}

\begin{abstract}
This study was conducted to examine the effects of eggshell membrane hydrolysates (ESMH) on the anti-inflammatory, anti-wrinkle, anti-microbial activity, and moisture-protection for cosmetic use. Whole ESMH (before fractionation), and fraction I $(>10 \mathrm{kDa})$, fraction II $(3-10 \mathrm{kDa})$, and fraction III $(<3 \mathrm{kDa})$ of the hydrolysates were assessed in this experiment. As lipopolysaccharide (LPS) and IFN- $\gamma$ caused the inflammation on Raw264.7 cell, whole ESMH and fraction I showed to be effective in inhibiting the induction of cell inflammation depending on the concentration, and also showed outstanding effect to suppress the skin inflammation. Fraction I inhibited collagenase and elastase activities to a greater extent than the other fractions, while all fractions had antibiotic effects at concentrations of $10 \mathrm{mg} / \mathrm{disc}$ and $20 \mathrm{mg} / \mathrm{disc}$. In addition, it showed the moisture protection effects of skin on the holding amount and losing amount of moisture in upper-inner arm of the human body with a relatively low loss rate in skin, which confirmed that the hydrolyzed fractions of ESM helps to form the superior protective layer of moisture. It was concluded that ESMH fractions with different molecular weights, especially the $10 \mathrm{kDa}$ fraction, have anti-lipopolysaccharide, anti-IFN- $\gamma$-induced inflammation, anti- collagenase and elastase activities, and thus can be used as a cosmetic agent to protect skin.
\end{abstract}

Key words: eggshell membrane, anti-inflammation, anti-aging, antibiotic, moisture protection

\section{Introduction}

Skin, the outer barrier of our body, interacts openly with an oxidative environment and is a major target of aging (Pillai et al., 2005). Factors that affect skin aging include genetic factors and external factors such as UV light, stress, and pollution (Kang, 1997). These factors cause cumulative alterations in skin structure and functions. In particular, solar UV irradiation makes a large contribution to skin aging (Rittié and Fisher, 2002), due to oxidative stress. Hydroxyl radicals and superoxide anions, which are referred to as reactive oxygen species, mediate oxidative stress. Treatments with ascorbic acid, tocopherols, and polyphenols, which are antioxidant agents, can increase the resistance of skin to oxidative stress and delay skin aging (Masaki, 2010). Symptoms of aging are due not only to oxidative stress, but also to damages caused to the skin

*Corresponding author: Youngjae Shin, Department of Environmental Horticulture, Dankook University, Cheonan 330-714, Korea. Tel: 82-41-550-3648, Fax: 82-41-559-7881, E-mail: ys 234@dankook.ac.kr by inflammatory reactions. Burns appear under extreme ultraviolet irradiation, and contact dermatitis is caused by irritant materials or allergens. Inflammatory cytokines are secreted to regenerate damaged skin. In particular, inflammatory cytokines are produced due to the action of nitric oxide synthase (NOS), which catalyzes the production of $\mathrm{NO}$, and acute and chronic inflammatory reactions are caused by iNOS, which is considered an inflammatory factor (Nathan, 1997). IFN- $\gamma$, TGF- $\beta$, TNF- $\alpha$, and IL-1, 2, -6 are inflammatory cytokines and excessive secretion of these cytokines can cause skin damages and even cancer (Willoughby, 1975). The stratum corneum has a barrier function, and lipids in the stratum corneum are involved in moisture maintenance, regulation of epithelial cell proliferation, cell aggregation, and desquamation (Blanken et al., 1989). However, the lipids in stratum corneum exposed to excessive ultraviolet light or inflammation become oxidized and causes skin aging with decreased elasticity due to dysfunction of oil and moisture maintenance. Therefore, maintaining moisture levels and the elasticity of skin is very important to keep skin healthy (Haratake et al., 1998; Jiang et al., 2007; Park, 2008). 
Recently, functional cosmetics have been developed to prevent oxidative stress in the skin. In Korea, functional cosmetic products include whitening, anti-wrinkle, and UV-light protection products (Kang, 1997). Retinol, adenosine, and (-) epigallocathechin-3-gallate (EGCG) are ingredients in anti-wrinkle functional cosmetics. These materials increase collagen production or inhibit collagenase activity (Chan et al., 2006; Griffiths et al., 1993; Sorg et al., 2006). An increase in elastase activity can result in wrinkle formation due to the decrease in the number of elastic fibers in the skin (Tsukahara et al., 2006). A major cause of reduction in skin elasticity and formation of wrinkles is increased elastase activity due to ultraviolet irradiation (Tsukahara et al., 2006). Increased collagen production can improve the appearance of wrinkles, but both elastin and elastic fibers can also improve wrinkle appearance (Antonicelli et al., 2007).

Cosmetics can be contaminated easily by microorganisms because they contain a variety of nutrients that can support microbial growth. Use of contaminated cosmetics can damage skin and even cause allergic reactions. Companies have focused on stabilizing raw materials and improving absorption of ingredients into the skin rather than developing new functional materials. However, there are consumer demands for cosmetic products that contain natural ingredients, which has resulted in the development of organic cosmetic products that have whitening or skin recovery properties (Park et al., 1993).

Eggshell membrane (ESM) is an organic substance that has been shown to increase cellular activity and collagen production. Furthermore, ESM prevents skin aging and reduces damages caused by UV-light and inflammation (Candilish et al., 1969). ESM is made of insoluble protein keratin, which is also present in feathers, hair, horns, scales, and nails. Keratin is very resistant to physical, chemical, and biological reactions (Vignardet et al., 1999). ESM has been suggested for use in formulations for moisturizer, wound recovery, skin growth, and anti-wrinkle agents (Kang, 1997; Park et al., 2012). Collagen improved the water content of stratum corneum and normalized transepidermal water loss (TEWL) in UVB-irradiated mice (Grubauer et al., 1989) and increased the water content of stratum corneum (Roskos and Guy, 1989) and skin viscoelasticity (Ohara et al., 2009) in humans. We showed in a previous study that whole eggshell membrane hydrolysates (ESMH) had a skin whitening effect because of their tyrosinase inhibiting and L-DOPA oxidizing activities. Furthermore, we confirmed the wound healing effects of ESMH using HaCaT cells (Park et al., 2012).
In this study, we investigated the anti-inflammatory, antiwrinkle, anti-microbial activity, and moisture-protection properties of whole eggshell membranes (ESMH) and various ESMH fractions: I ( $>10 \mathrm{kDa})$, fraction II $(3-10 \mathrm{kDa})$, and fraction III $(<3 \mathrm{kDa})$.

\section{Materials and Methods}

\section{Eggshell membrane hydrolysates}

The egg shell membrane used in this study was provided by Sungkyun Biotech Co., Ltd. The $100 \mathrm{~g}$ of dried egg shell membranes were added to $1100 \mathrm{~mL}$ of distilled water, $2 \mathrm{~N} \mathrm{NaOH}$ and $40 \%$ EtOH before being kept at $70^{\circ} \mathrm{C}$ for $2 \mathrm{~h}$ for the reactions. After the reactions, $99 \%$ acetic acid was added for neutralization ( $\mathrm{pH} 7.0)$ and 40 $\mathrm{g}$ of the activated carbon was added for decolorization for $20 \mathrm{~min}$. The extract was filtered through a Whatman No.1 filter paper and desalinated using Micro acilyzer G3 (Asashi Kasei Corp., Japan). It was then evaporated and freeze-dried (FD 3, Heto, Gydevang, Denmark). Then, the ESMHs were divided into three fragments: fraction I $(>10$ $\mathrm{kDa})$, fraction II $(3-10 \mathrm{kDa})$, and fraction III $(<3 \mathrm{kDa})$ as described previously (Park et al., 2012).

\section{Anti-inflammatory activity}

\section{Cell culture and MTT assay}

Lipopolysaccharide (LPS) was obtained from Sigma Chemical Co., USA and IFN- $\gamma$ from LG Life Sciences, Korea. All laboratory supplies, including the cell culture dishes, were from Falcon. RAW 264.7 cells (mouse macrophage cell line) were obtained from the Korean Cell Line Bank (KCLB). RAW 264.7 cells were grown in Dulbecco's Modified Eagle's Medium (DMEM, WelGENE Inc., USA) supplemented with 10\% heat-inactivated fetal bovine serum (FBS) and 1\% penicillin-streptomycin (BioWhittaker Inc., USA). When cells reached $90 \%$ confluence, they were centrifuged at 2,000 rpm for $3 \mathrm{~min}$ and then diluted at a 1:5 ratio.

Cell viability was assessed using the MTT assay process of Carmichael (1988). RAW 264.7 cells were placed in a 24 -well plate at a concentration of $1 \times 10^{6} / \mathrm{mL}$ and the plate was incubated in a $5 \% \mathrm{CO}_{2}$ incubator at $37^{\circ} \mathrm{C}$ for $24 \mathrm{~h}$ to allow the cells to attach to the bottom of each well. At the end of incubation, the medium was removed, 100 $\mathrm{mL}$ of $0.5 \mathrm{mg} / \mathrm{mL} 3$-(4,5-dimethyl-2-thiazolyl)-2,5-diphenyl-2H-tetrazolium bromide (MTT) solution was added to each well, and the plate was placed in a $5 \% \mathrm{CO}_{2}$ incubator at $37^{\circ} \mathrm{C}$, without light, and incubated for $4 \mathrm{~h}$. DMSO 
was then added, and the plate was left at room temperature for $5 \mathrm{~min}$ before light absorption was measured at $540 \mathrm{~nm}$ using an ELISA microplate reader. Cell survival was then calculated as a percentage.

\section{Nitric oxide (NO) inhibition assay}

RAW 264.7 cells $(500 \mu \mathrm{L})$ were plated into each of the 24 wells in a 24-well cell culture plate at a concentration of $1 \times 10^{6} / \mathrm{mL}$ followed by incubation in a $5 \% \mathrm{CO}_{2}$ incubator for $4 \mathrm{~h}$ at $37^{\circ} \mathrm{C}$. Medium used during the incubation was discarded and new medium containing diluted eggshell membrane, LPS, and IFN- $\gamma$ was added, and then incubated for $24 \mathrm{~h}$ at $37^{\circ} \mathrm{C}$. The amount of NO produced was assessed by adding Griess reagent $[1 \%(\mathrm{w} / \mathrm{v})$ sulfanilamide, $0.1 \%(\mathrm{w} / \mathrm{v}) \mathrm{N}-(1-$-naphthyl)ethylenediamine in $2.5 \%(\mathrm{v} / \mathrm{v})$ phosphoric acid] for $10 \mathrm{~min}$ in a 96-well plate. The absorbance at $540 \mathrm{~nm}$ was measured using an ELISA plate reader. A calibration curve was made using serial dilutions $(1-100 \mu \mathrm{M})$ of sodium nitrite $\left(\mathrm{NaNO}_{2}\right)$.

\section{Anti-wrinkle activity}

\section{Collagenase inhibition assay}

We measured the amount of peptides fragmented by collagenase using the ninhydrin reaction. Collagen Type I (Sigma Chemical Co., USA) was added to TES (N-[Tris (hydroxyl methyl) methyl]-2- aminoethanesulfonic acid sodium salt, Sigma Chemical Co., USA), buffer, diluted samples, collagenase, and Clotridium histolyticum collagenase Type IV (Sigma Chemical Co., USA) solution, and the sample was placed in a shaking incubator for $5 \mathrm{~h}$ at $37^{\circ} \mathrm{C}$ and centrifuged for $5 \mathrm{~min}$ at $2000 \mathrm{rpm}$. The supernatant was collected and mixed with ninhydrin (2,2-Dihydroxy- 1,3-indanedione, Sigma Chemical Co., USA) reaction buffer, which was heated with a circulator (Vision scientific co., Ltd., Korea) for $10 \mathrm{~min}$ at $80^{\circ} \mathrm{C}$ and then frozen. Solutions were then mixed with isopropanol at a $1: 1$ ratio and centrifuged for $10 \mathrm{~min}$ at $12,000 \mathrm{rpm}$ at $4^{\circ} \mathrm{C}$. The resulting supernatant was placed in the wells of a 96well plate, and light absorption at $600 \mathrm{~nm}$ was measured using an ELISA plate reader. Epigallocatechin gallate (EGCG, Sigma Chemical Co., USA) was used as a control.

\section{Elastase inhibition assay}

The elastase inhibition activity was determined using the method of James et al., (1996). A Trizma base (Sigma Chemical Co., USA) buffer and eggshell membrane fractions were placed in a 96-well plate, and then $\mathrm{N}$-succinyl-
Ala-Ala-Ala-p-nitroanilide (Sigma Chemical co., USA) $(8.8 \mathrm{mM})$ was added to each well. Elastase (Sigma Chemical Co., USA) solution was added to each well prior to incubation for $15 \mathrm{~min}$ at $25^{\circ} \mathrm{C}$, and then the light absorption at $410 \mathrm{~nm}$ was read using a ELISA reader. EGCG was used as a control. Elastase inhibition was calculated using the following equation:

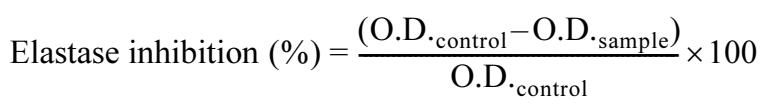

\section{Anti-microbial activity}

\section{Strains and mediums}

All bacterial strains used in this study were supplied by the Biological Resources Center. The media used for this study, tryptic soy broth (TSB) and de Man, Rogosa, Sharpe (MRS) medium, were purchased from Difco Laboratories (Sperks, USA).

\section{Paper disc assay}

To assess the antimicrobial effects of eggshell membranes against skin pathogens, we used the disc diffusion method. Pathogens were cultivated in liquid medium for 18 to $24 \mathrm{~h}$, and then the solution was added to new liquid medium for $4 \mathrm{~h}$ before being poured as liquid agar, which set at room temperature. Sterilized filter paper discs $(8$ $\mathrm{mm}$, Advantec, Japan) were placed in medium, and then $20 \mu \mathrm{L}$ of eggshell sample was allowed to soak into each disk for 18 to $24 \mathrm{~h}$. The clear zone around the discs was then measured. Ampicillin (Sigma Chemical Co., USA) was used as a positive control, and each test was performed three times independently.

\section{Moisture-protection}

Measurement of skin moisture and effectiveness of moisture loss reduction

National DR-1 was used to measure skin capacitance and MPA5-CK to study transepidermal water loss (TEWL) in healthy male and female subjects without any skin conditions such as allergies or any medical history of relevant diseases. Thirty minutes before the test, test subjects were placed in an indoor environment at a temperature between 20 and $22^{\circ} \mathrm{C}$ and a humidity level between 40 and $60 \%$. Skin of the subjects' lower arms was measured using the tape stripping method (Prall, 1966). Skin moisture content level (\% wet basis) was measured at $0,1,3$, and $6 \mathrm{~h}$ after breakage and TEWL was measured in $\mathrm{g} / \mathrm{h} / \mathrm{m}^{2}$. 


\section{Statistical analysis}

Data were analyzed using one-way analysis of variance (ANOVA) followed by Tukey's and Duncan's tests. Analyses were implemented in IBM SPSS Statistics 19.0 (IBM Corporation, Somers, USA) and results were considered significant when $p<0.05$, unless otherwise stated.

\section{Results and Discussion}

\section{Anti-inflammatory activity}

\section{Nitric oxide (NO) inhibition assay}

Nitric oxide normally plays an important role in killing bacteria and tumor cells, but an excess level of NO can lead to the destruction of host cells, disruption of hormonal balance, and tissue damage as a result of an inflammatory response (Chiou et al., 2001). Inducible NOS (iNOS) is released upon exposure to stimulants such as LPS, INF- $\gamma$, and tumor TNF- $\alpha$. NO produced by the catalytic action of iNOS is very unstable and converts to nitrite and nitrate easily. When these molecules come in contact with oxygen, peroxynitrite is formed, which can damage cells and induce them to produce insulin (Bredt, 1994). Such an inflammatory response is due to the skin trying to protect itself from bacterial infection while recovering. Fig. 1 shows the level of NO suppression when RAW 264.7 cells, activated by LPS and INF- $\gamma$, were treated with whole ESMH and fractions I, II, and III at concentrations of $0.01 \mathrm{mg} /$ $\mathrm{mL}, 0.1 \mathrm{mg} / \mathrm{mL}$, and $1 \mathrm{mg} / \mathrm{mL}$. While control cells produced $10 \mu \mathrm{M}$ NO when treated with LPS and INF- $\gamma$, cells

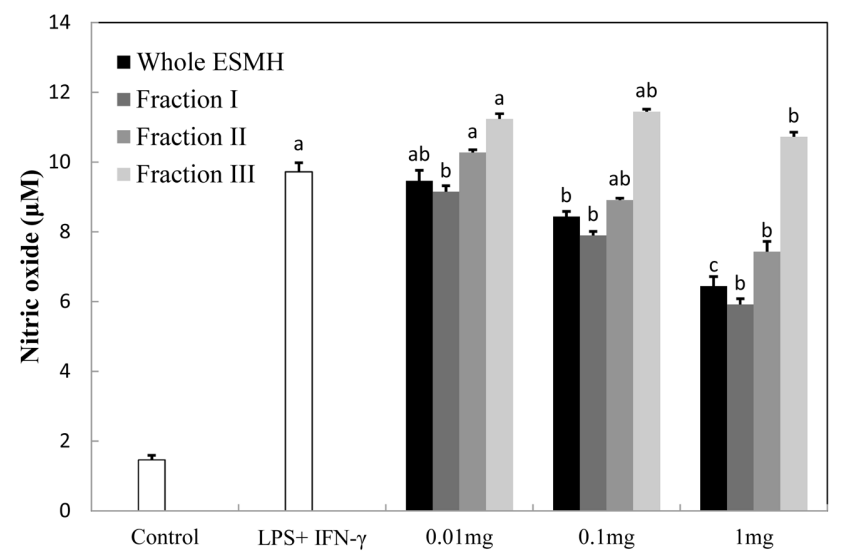

Fig. 1. Effect of the egg shell membrane hydrolysates fractionated by molecular weight on Nitric oxide (NO) production. RAW264.7 cells were treated with LPS (100 ng/ $\mathrm{ml}+$ in IFN- $\gamma(10$ unit $/ \mathrm{ml})$ the presence of various concentrations of fraction. NO levels were measured in the cell culture media by ELISA. The data presented the mean values \pm standard deviation of three independent experiments. treated with $1 \mathrm{mg} / \mathrm{mL}$ whole ESMH and fraction I produced 6.7 $\mu \mathrm{M}$ and 6.2 $\mu \mathrm{M}$ NO, respectively. Smaller molecular mass components of ESMH (fraction III) did not reduce production of NO. In summary, because the $10 \mathrm{kDa}$ ESMH fraction significantly suppressed an inflammatory response in the skin, it may have anti-inflammatory potential in cosmetic products.

\section{Anti-wrinkle activity}

\section{Collagenase inhibition assay}

Collagenase is an enzyme that hydrolyzes collagen thereby causing loss of hydration and elasticity in skin, resulting in wrinkle formation. We examined whether eggshell membranes could inhibit collagenase using a collagenase inhibition assay. Fig. 2 shows the amount of peptides produced due to collagenase activity at $1 \mu \mathrm{g} / \mathrm{mL}, 10 \mu \mathrm{g} / \mathrm{mL}$, and $30 \mu \mathrm{g} / \mathrm{mL}$ of whole ESMH and its fractions. Whole ESMH inhibited collagenase activity by $14 \pm 2 \%, 28 \pm 1 \%$, and $31 \pm 1 \%$, fraction I by $16 \pm 1 \%, 30 \pm 2 \%, 34 \pm 2 \%$, fraction II by $2 \pm 2 \%, 26 \pm 2 \%$, and $29 \pm 1 \%$, and fraction III by $8 \pm 1 \%, 24 \pm 3 \%$, and $26 \pm 2 \%$, respectively. EGCG (positive control) inhibited collagenase activity by $19 \pm 1 \%, 38 \pm 3 \%$, and $40 \pm 1 \%$, respectively. EGCG is replacing retinol as an ingredient in anti-wrinkle formulations and also stimulates collagen production. Although all eggshell fractions had lower collagenase inhibitory activity than EGCG (the positive control), they did decrease collagenase activity, with fraction I showing the highest inhibition rate. Tissue inhibitors of metalloprotease-1 (TIMP-1), which is known as a collagenase- 1 inhibitor, have cysteine disulfide bonds in the structure as well as valine, serine, and leucine resi-

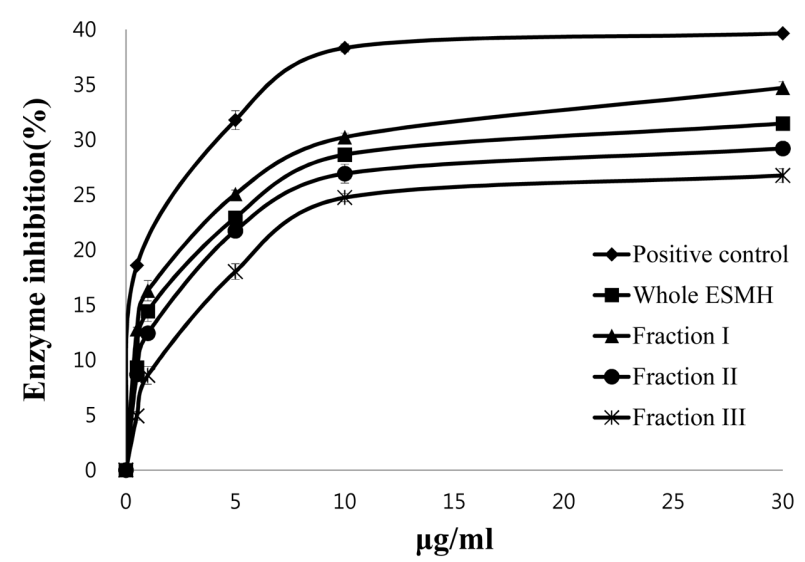

Fig. 2. Inhibition of collagenase by EGCG (positive control) and egg shell membrane hydrolysates (ESMH) fractionated by molecular weight. The data presented the mean values \pm standard deviation of three independent experiments. 


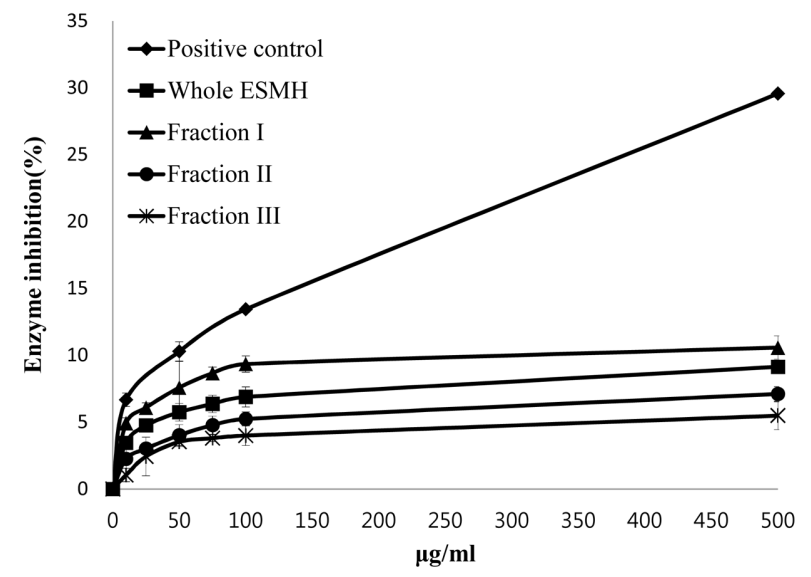

Fig. 3. Inhibition of Elastase by EGCG (positive control) and egg shell membrane hydrolysates (ESMH) fractionated by molecular weight. The data presented the mean valueststandard deviation of three independent experiments.

dues, and inhibit collagenase I activity by binding to its active site (Nagase et al., 2006). Eggshell membrane hydrolysates (ESMH) contain lots of hydrophobic amino acids such as leucine and valine (Yi et al., 2004) that may bind to the active site of collagenase. This explains the inhibitory activity of ESMH, although further studies are required to investigate this hypothesis.

\section{Elastase inhibition assay}

Elastin, an elastic fiber, is known to have significant antiwrinkling properties along with collagen. In skin exposed to UV light, there is an increase in the production of elastase and a concomitant decrease in skin elasticity, followed by deformation and collapse of the skin to form wrinkles (Tsuji et al., 2001; Tsukahara et al., 2001). To assess the anti-wrinkle activity of eggshell membrane, the ability of whole ESMH and fractions I, II, and III at concentrations of $10 \mu \mathrm{g} / \mathrm{mL}, 100 \mu \mathrm{g} / \mathrm{mL}$, and $500 \mu \mathrm{g} / \mathrm{mL}$ to inhibit elastase activity was evaluated. EGCG (positive control) inhibited elastase activity by $\pm 1 \%, 13 \pm 2 \%$, and $29 \pm 3 \%$, while ESMH inhibited the activity by $3 \pm 2 \%, 6 \pm$ $1 \%$, and $9 \pm 3 \%$, fraction I by $5 \pm 1 \%, 9 \pm 2 \%$, and $11 \pm 2 \%$; fraction II by $2 \pm 2 \%, 5 \pm 2 \%$, and $7 \pm 1 \%$; and fraction III by $1 \pm 1 \%, 4 \pm 3 \%$, and $5 \pm 2 \%$, respectively (Fig. 3 ). As stated above, EGCG is used as an alternative to retinol in skin formulations. Although eggshell fractions inhibited elastase activity less than the positive control, elastase activity did decrease, and this was most marked for fraction I. The ability of eggshell membrane to inhibit both elastase activity and collagenase activity indicated that it has a potential for practical application in anti-wrinkle cosmetics.

\section{Anti-microbial activity}

\section{Paper disc assay}

Compounds from eggs that are known to have antimicrobial properties and the egg compounds that are currently marketed include lysozyme, conalbumin, avidin, and lactoferrin (Ashton and Busta, 1968; Oram and Reiter, 1968). To examine the antimicrobial activity of eggshell membrane hydrolysates, various pathogenic bacteria were treated with whole ESMH and fractions I, II, and III at concentrations of $0.1 \mathrm{mg} / \mathrm{disc}, 1 \mathrm{mg} /$ disc, $10 \mathrm{mg} /$ disc, and 20 $\mathrm{mg} / \mathrm{disc}$. Results are shown in Table 1.

Staphylococcus epidermidis, Staphylococcus aureus, and Bacillus subtilis, which are Gram-positive bacteria, and Klebsiella pneumoniae and Serratia marcescens, which

Table 1. Antimicrobial activity of the egg shell membrane hydrolysates fractionated by molecular weight

\begin{tabular}{|c|c|c|c|c|c|c|c|c|c|c|c|c|c|c|c|c|c|}
\hline \multirow{2}{*}{ Strains } & \multirow{2}{*}{$\frac{\text { P.c* }}{\text { Amp. }}$} & \multicolumn{4}{|c|}{ Whole ESMH } & \multicolumn{4}{|c|}{ Fraction I } & \multicolumn{4}{|c|}{ Fraction II } & \multicolumn{4}{|c|}{ Fraction III } \\
\hline & & 20 & 10 & 1 & 0.1 & 20 & 10 & 1 & 0.1 & 20 & 10 & 1 & 0.1 & 20 & 10 & 1 & 0.1 \\
\hline Staphy. aureus & ++ & ++ & ++ & - & - & ++ & - & - & - & ++ & ++ & - & - & ++ & ++ & - & - \\
\hline Staphy. epidermidis & - & - & - & - & - & - & - & - & - & - & - & - & - & - & - & - & - \\
\hline L. lactis & - & - & - & - & - & - & - & - & - & - & - & - & - & - & - & - & - \\
\hline B. subtilis & + & + & + & - & - & + & - & - & - & + & + & - & - & + & + & - & - \\
\hline K.pneumoniae & + & + & + & + & + & + & + & + & + & + & + & + & + & + & + & + & + \\
\hline Shigella flexneri & - & - & - & - & - & - & - & - & - & - & - & - & - & - & - & - & - \\
\hline Proteus vulgaris & - & - & - & - & - & - & - & - & - & - & - & - & - & - & - & - & - \\
\hline Enterobacter cloacae & - & - & - & - & - & - & - & - & - & - & - & - & - & - & - & - & - \\
\hline E. coli & + & - & - & - & - & - & - & - & - & - & - & - & - & + & - & - & - \\
\hline S. marcescens & ++ & ++ & + & - & - & + & - & - & - & ++ & + & - & - & ++ & + & - & - \\
\hline Citrobacter freundii & - & - & - & - & - & - & - & - & - & - & - & - & - & - & - & - & - \\
\hline B. subtilis & + & + & + & - & - & + & - & - & - & + & + & - & - & + & + & - & - \\
\hline
\end{tabular}

Growth inhibition size of clear zone: -, not detected; +, less than $10 \mathrm{~mm}$; ++, more than $10 \mathrm{~mm}$. Whole ESMH means egg shell membrane hydrolysates before fractionation, Fraction I (above $10 \mathrm{kDa}$ of ESMH), Fraction II (3-10 kDa of ESMH), Fraction III (below $3 \mathrm{kDa}$ of ESMH). *Positive control. 
are Gram-negative bacteria, are present in atmosphere as well as on human skin. They can cause symptoms of infection such as skin rashes and blisters. We used ampicillin as a control. Discs containing eggshell fractions at 10 $\mathrm{mg} /$ disc and $20 \mathrm{mg} /$ disc showed antimicrobial activities against both Gram-positive and Gram-negative bacteria, but their anti-microbial activity against Gram positive bacteria was more pronounced than that against Gram negative bacteria. In summary, eggshell membrane hydrolysates showed a high level of antimicrobial activity against several bacteria, including $S$. aureus, indicating that they could have practical application in acne formulations.

\section{Moisture-protection}

\section{Assessment of moisture in the skin and TEWL}

The stratum corneum, the uppermost layer of the skin, is $20-40 \mu \mathrm{m}$ thick and consisted of various layers. It protects the human body from external forces and pressure, and also plays a role in preventing microbes from entering the body while controlling the intake and release of gases and water (Jacobi, 1959; Middleton, 1974). To assess skin hydration levels in vitro, skin elasticity is assessed; to assess skin hydration in vivo, transepidermal water loss (TEWL), skin elasticity, and skin formation are assessed. We compared the effects of treatment with whole ESMH and fractions I, II, and II at $1 \mathrm{mg} / \mathrm{mL}$ and a control on skin hydration levels after stimulation (tape stripping). Results are summarized in Fig. 4 and 5. After 0, 1, 3, and $6 \mathrm{~h}$, the control had an average TEWL value of $36 \pm 1 \mathrm{mg} / \mathrm{m}^{2} \mathrm{~h}$ and TEWL values of $41 \pm 1,45 \pm 1,48 \pm 1$, and $44 \pm 1 \mathrm{mg} / \mathrm{m}^{2} \mathrm{~h}$, respectively. Whole ESMH TEWL values were $36 \pm 1,34 \pm 1$, $37 \pm 3$, and $35 \pm 2 \mathrm{mg} / \mathrm{m}^{2} \mathrm{~h}$, fraction I values were $38 \pm 1,32 \pm$ $1,36 \pm 1$, and $36 \pm 2 \mathrm{mg} / \mathrm{m}^{2} \mathrm{~h}$, fraction II values were $37 \pm 1$, $33 \pm 1,35 \pm 2$, and $36 \pm 2 \mathrm{mg} / \mathrm{m}^{2} \mathrm{~h}$, and fraction III values were $36 \pm 1,36 \pm 1,39 \pm 1$, and $35 \pm 2 \mathrm{mg} / \mathrm{m}^{2} \mathrm{~h}$ after $0,1,3$, and $6 \mathrm{~h}$, respectively. In terms of moisture retention in the skin, the control with no stimulation showed an average value of $30 \pm 1 \%$ with no change over time, whereas the control with stimulation had moisture retention values of $30 \pm 1 \%, 29 \pm 1 \%, 30 \pm 1 \%$, and $31 \pm 1 \%$. Whole ESMH treatment resulted in water retention values of $31 \pm 1,32 \pm 1$, $34 \pm 1$, and $33 \pm 2 \mathrm{mg} / \mathrm{m}^{2} \mathrm{~h}$, fraction I values of $30 \pm 1,32 \pm 1$, $33 \pm 1$, and $32 \pm 1 \mathrm{mg} / \mathrm{m}^{2} \mathrm{~h}$, fraction II values of $31 \pm 1,31 \pm 1$, $32 \pm 2$, and $32 \pm 1 \mathrm{mg} / \mathrm{m}^{2} \mathrm{~h}$, and fraction III values of $30 \pm 1$, $31 \pm 1,32 \pm 1$, and $31 \pm 1 \mathrm{mg} / \mathrm{m}^{2} \mathrm{~h}$ for the $0,1,3$, and $6 \mathrm{~h}$ time points. In conclusion, these findings showed that, compared to the control with stimulants, the fragments showed significantly higher levels of moisture retention, relatively

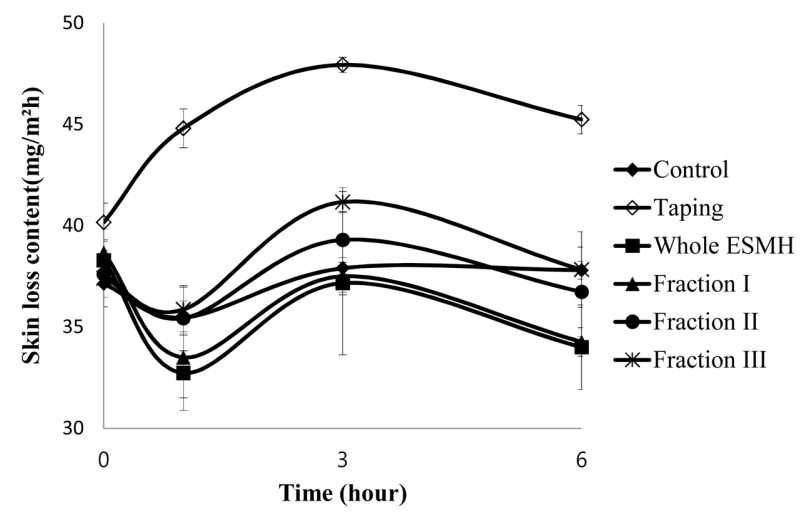

Fig. 4. Comparison of the trans-epidermal water loss (TEWL) of volunteer's forearm area before and after the treatment of the egg shell membrane hydrolysates (ESMH) fractionated by Molecular Weight.

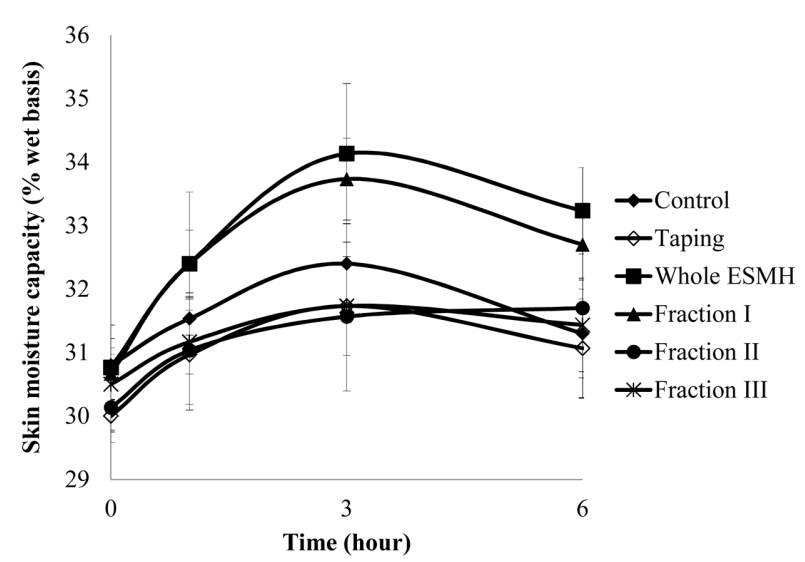

Fig. 5. Comparison of skin moisture of the volunteer's forearm area before and after the treatment of the egg shell membrane hydrolysates (ESMH) fractionated by Molecular Weight.

lower levels of damage to the skin and the formation of improved moisture protection for the skin.

\section{Acknowledgements}

This work (Grants No. 00045151) was supported by Business for Academic-industrial Cooperative establishments funded Korea Small and Medium Business Administration in 2011.

\section{References}

1. Antonicelli, F., Bellon, G., Debelle, L., and Hornebeck, W. (2007) Elastin-elastases and inflamm aging. Curr. Top. Dev. Biol. 79, 99-155.

2. Ashton, D. H. and Busta, F. F. (1968) Relief of casein inhibition of Bacillus stearothermophilus by iron, calcium, and magnesium. Appl. Microbiol. 16, 628-635. 
3. Blanken, R., Van Vilsteren, M. J. T., Tupker, R. A., and Conraads, J. (1989) Effect of mineral oil and linoleic-acid-containing emulsions on the skin vapour loss of sodium-lauryl sulphate-induced irritant skin reactions. Contact Dermatitis 20, 93-97.

4. Bredt, D. S. and Snyder, S. H. (1994) Nitric oxide: A physiologic messenger molecule. Annu. Rev. Biochem. 63, 175-195.

5. Candilish, J. K. and Scougall, R. K. (1969) L-5-hydroxylysine as aconstituent of the shell membrane of the hen's egg. Int. $J$. Protein Res. 1, 299-306.

6. Carmichael, W. W. (1988) Toxins of freshwater algae, In A. T. Tu (ed.). Handbook of natural toxins, Marine toxins and venoms. Marcel Dekker, Inc., New York. 3, 121-147.

7. Chan, E. S., Fernandez, P., Merchant, A. A., Montesinos, M. C., Trzaska, S., Desai, A., Tung, C. F., Khoa, D. N., Pillinger, M. H., Reiss, A. B., Tomic-Canic, M., Chen, J. F., Schwarzschild, M. A., and Cronstein, B. N. (2006) Adenosine A2A receptors in diffuse dermal fibrosis: Pathogenic role in human dermal fibroblasts and in a murine model of scleroderma. Arthritis Rheum. 54, 2632-2642.

8. Chiou, W. F., Chou, C. J., and Chen, C. F. (2001) Camptothecin suppresses nitric oxide biosynthesis in Raw264.7 macrophages. Life Science 69, 625-635.

9. Griffiths, C. E., Russman, A. N., and Majmudar, G. (1993) Restoration of collagen formation in photodamaged human skin by tretinoin (retinoic acid). New Engl. J. Med. 329, 530-535.

10. Grubauer, G., Elias, P. M., and Feingold, K. R. (1989) Transepidermal water loss: The signal for recovery of barrier structure and function. J. Lipid Res. 30, 323-333.

11. Haratake, A., Uchida, Y., and Schmuth, M. (1998) UVB-induced alterations in permeability barrier function: Roles for epidermal hyperproliferation and thymocyte-mediated response. J. Invest. Dermatol. 108, 769-775.

12. Jacobi, O. K. (1959) About the mechanism of moisture regulation in the horny layer of skin. Proc. Sci. Sec. Toilet. Goods Assoc. 31, 22-24.

13. James, A. E. K., Timothy, D. W., and Gorden, L. (1996) Inhibition of human leujocyte and porcine pancreatic elastase by homologues of bovine pancreatic tyrosinase inhibitors. Biochemistry 35, 9090-9096.

14. Jiang, S. J., Chu, A. W., Lu, Z. F., Pan, M. H., Che, D. F., and Zhou, X. J. (2007) Ultraviolet B-induced alterations of the skin barrier and epidermal calcium gradient. Exp. Dermatol. 16, 985-992.

15. Kang, H. H. (1997) Anti-aging in cosmetics. J. Soc. Cosmet. Scientists Korea 23, 57-73.

16. Masaki, H. (2010) Role of antioxidants in the skin: Antiaging effects. J. Dermatol. Sci. 58, 85-90.

17. Middleton, J. D. (1974) Development of a skin cream designed to reduce dry and flaky skin. J. Soc. Cosmet. Chem. 25, 519534.

18. Nagase, H., Visse, R., and Murphy, G. (2006) Structure and function of matrix metalloproteinases and TIMPs. Cardiovasc. Res. 69, 562-573.

19. Nathan, C. (1997) Inducible nitric oxide synthase: What difference does it make? J. Clin. Invest. 94, 5243-5248.
20. Ohara, H., Ito, K., Iida, H., and Matsumoto, H. (2009) Improvement in the moisture content of the stratum corneum following 4 weeks of collagen hydrolysate ingestion. Food Sci. Tech. Res. 56, 137-145

21. Oram, J. D. and Reiter, B. (1968) Inhibition of bacteria by lactoferrin and other iron-chelating agents. Biochem. Biophys. Acta. 170, 351-365.

22. Park, C. S. (2008) Skin barrier and beauty foods. Food Sci. Indus. 40, 19-26.

23. Park, J. G., Hyun, J. W., Lim, K. H., Shin, J. E., Won, Y. J., Yi, Y. D., Shin, K. H., Chang, I. M., and Woo, W. S. (1993) Antineoplastic effects from traditional medicinal plants. Kor. J. Pharmacogn. 24, 223-230.

24. Park, K. M., Yoo, J. H., and Shin, Y. G. (2012) Effects of egg shell membrane hydrolysates on skin whitening, wound healing, and UV-protection. Korean J. Food Sci. An. 32, 308-315.

25. Pillai, S., Oresajo, C., and Hayward, J. (2005) Ultraviolet radiation and skin aging: Roles of reactive oxygen species, inflammation and protease activation, and strategies for prevention of inflammation-induced matrix degradation - A review. Int. J. Cosmet. Sci. 27, 17-34.

26. Prall, J. K. (1966) Scaliness of human skin. Archives De Biochemie Et Cosmetologie. 9, 87-88.

27. Rittié, L. and Fisher, G. J. (2002) UV-light-induced signal cascades and skin aging. Ageing Res. Rev. 1, 705-720.

28. Roskos, K. V. and Guy, R. H. (1989) Assessment of skin barrier function using transepidermal water loss: Effect of age. Pharm Res. 6, 949-953.

29. Sorg, O., Antille, C., Kaya, G., and Saurat, J. H. (2006) Retinoids in cosmeceuticals, Dermatol. Ther. 19, 289-296.

30. Tsuji, N., Moriwaki, S., Suzuki, Y., Takema,Y., and Imokawa, G. (2001) The role of elastases secreted by fibroblasts in wrinkle formation: Implication through selective inhibition of elastase activity. Photochem. Photobiol. 74, 283-290.

31. Tsukahara, K., Nakagawa, H., Moriwaki, S., Takema, Y., Fujimura, T., and Imokawa, G. (2006) Inhibition of ultravioletB-induced wrinkle formation by an elastase-inhibiting herbal extract: Implication for the mechanism underlying elastaseassociated wrinkles. Int. J. Dermatol. 45, 460-480.

32. Tsukahara, K., Takema, Y., Moriwaki, S., Tsuji, N., Suzuki, Y., and Fujimura, T. (2001) Selective inhibition of skin fibroblast elastase elicits a concentration - dependent prevention of ultraviolet B-induced wrinkle formation. J. Invest. Dermatol. 117, 671-677.

33. Vignardet, C. G., Friedrich, Y. C., and Millet, J. (1999) A first order experiment design to assess soluble proteins released by a new keratinase from Doratomyces microsporus on human substrate. Int. J. Pharm. 191, 95-102.

34. Willoughby, D. A. (1974) Human arthritis applied to animal models. Towards a better therapy. Ann. Rheum. Dis. 34, 471478.

35. Yi, F., Guo, Z. X., Zhang, L. X., Yu, J., and Li, Q. (2004) Soluble eggshell membrane protein: preparation, characterization and biocompatibility. Biomaterials 25, 4591-4599.

(Received 2013.6.21/Revised 2013.11.22/Accepted 2014.1.8) 